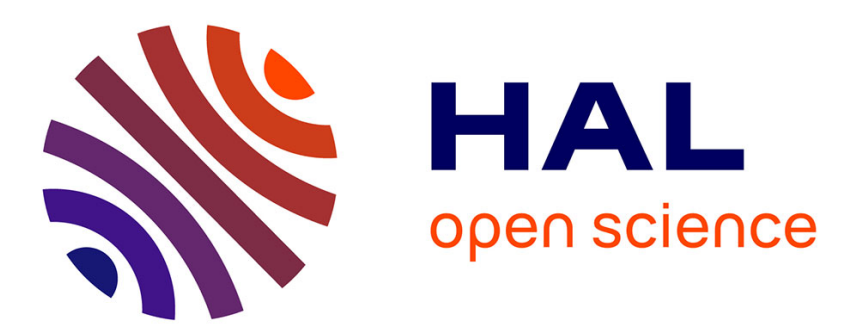

\title{
Pressure sensitivity of plasticity in metallic glasses below glass transition: a literature review
}

Vincent Keryvin, Jean-Sébastien Brest, Patrice Longère, Adrien Anguet

\section{To cite this version:}

Vincent Keryvin, Jean-Sébastien Brest, Patrice Longère, Adrien Anguet. Pressure sensitivity of plasticity in metallic glasses below glass transition: a literature review. THERMEC 2011, Aug 2011, Quebec, Canada. pp.1318-1323, 10.4028/www.scientific.net/MSF.706-709.1318 . hal-00977305

\section{HAL Id: hal-00977305 https://hal.science/hal-00977305}

Submitted on 10 Apr 2014

HAL is a multi-disciplinary open access archive for the deposit and dissemination of scientific research documents, whether they are published or not. The documents may come from teaching and research institutions in France or abroad, or from public or private research centers.
L'archive ouverte pluridisciplinaire HAL, est destinée au dépôt et à la diffusion de documents scientifiques de niveau recherche, publiés ou non, émanant des établissements d'enseignement et de recherche français ou étrangers, des laboratoires publics ou privés. 


\title{
Pressure sensitivity of plasticity in metallic glasses below glass transition: a literature review
}

\author{
Vincent Keryvin ${ }^{1,2, a}$, Jean-Sebastien Brest ${ }^{1, b}$, Patrice Longere ${ }^{1,3, c}$ and Adrien \\ Anguet $^{2}$ \\ ${ }^{1}$ Universite Europeenne de Bretagne, Universite de Bretagne-Sud, LIMATB EA 4250, Campus de Saint \\ Maude, BP 92116, 56321 Lorient Cedex, France \\ ${ }^{2}$ Universite Europeenne de Bretagne, Universite de Rennes 1, LARMAUR ERL CNRS 6274, Campus de \\ Beaulieu, 35042 Rennes, France \\ ${ }^{3}$ Universite de Toulouse, ISAE, ICA EA 814, 10 av. E. Belin, BP 54032, 31055 Toulouse cedex 4, France \\ ${ }^{a}$ vincent.keryvin@univ-ubs.fr, ${ }^{b}$ jean-sebastien.brest@univ-ubs.fr, ${ }^{c}$ patrice.longere@isae.fr
}

Keywords: metallic glass, indentation, constraint factor, plasticity, pressure, temperature, glass transition.

\begin{abstract}
This paper deals with the pressure dependence of plasticity in metallic glasses below glass transition. Recent results indicate that some metallic glasses have such a dependence and that it increases with temperature (Keryvin et al., Phil. Mag., 88, 1773, 2008). We investigate the possibility that such a situation could be a common feature for all metallic glasses by performing a literature review. Results indicate that it is not straightforward to draw decisive conclusions.
\end{abstract}

\section{Introduction}

Metallic glasses (or amorphous alloys) are relatively new materials, first discovered in the 1960s, which have attracted great interest for their tremendously high mechanical properties, particularly their strength, resilience, elastic deformation [1] and fracture toughness [2]. Available in bulk form, especially since the 1990s, they are usually quasi-brittle in uniaxial loading. The knowledge of plastic mechanisms and the relationships with their structure at the nanometer scale (short-to-medium range order) is still an active topic. Due to the absence of long-range order and crystalline defects such as dislocations, anelastic and inelastic mechanisms are to be looked at the atomistic scale. Active concepts attempting to explain these mechanisms are double: free volume theory and the shear transformation zone (STZ) concept. The former is essentially a diffusion-like mechanism. The latter considers that a local cluster of atoms undergo a shear transformation going from a a stable configuration to another one crossing transiently a configuration of higher energy and volume. These STZ may grow in number and coalesce to form shear bands (localised plasticity) below glass transition. This mechanism infers first that pressure plays a role in making the activation of STZ more difficult (pressure dependence) and that there is some creation of disorder and volume (dilatation). At the microscopic scale, molecular dynamics simulations confirmed the pressure sensitivity of plasticity [3].

Recently Schuh et al. compiled experimental mechanical results showing that yield strength decreases quasi linearly with stress triaxiality or vice versa increases with pressure [1]. However in some very brittle systems, the use of conventional testing techniques (tension, compression, bending...) to investigate either yield strength or plastic deformation is precluded. On the contrary, it has been also shown that indentation techniques allow to probe the pressure sensitivity of plasticity [4]. These techniques, apart from requiring small volumes and an easy sample preparation, develop very high pressures underneath the indenter in addition to shear stresses, allowing to probe, more adequately than conventional techniques, the pressure sensitivity of 
the plastic response of the material [5]. Two main indentation features are used for extracting qualitatively and quantitatively the degree of pressure sensitivity [6]. The first one uses the ratio hardness-to-yield strength while the other requires a reverse analysis of the load-displacement curve. As for the former, in the fully plastic regime of indentation, where the plastic region is no longer fully contained by the surrounding elastic one, this ratio is called the constraint factor C. Its value is below 3, when pressure insensitive materials like most crystalline metals are indented. Higher values of $\mathrm{C}$ imply a pressure sensitivity of plasticity. Recent studies shown that $\mathrm{C}$ increases with temperature from low temperatures up to below the glass transition [6, 7]. It has even been shown that some amorphous polymers follow the same behaviour with very comparable levels of pressure sensitivities [8]. In this paper we examine the possibility that such a situation could be a feature for all metallic glasses.

\section{Results of literature survey}

In this section, we collect data from literature papers on many glass compositions, including $\mathrm{Fe}, \mathrm{Cu}, \mathrm{Ni}, \mathrm{Zr}, \mathrm{Mg}$, La, Au, Pd, Pt-base alloys. In particular, we collect hardness $(\mathrm{H})$ and compressive yield strength $(\mathrm{Y})$ values as well as yield strains and glass transition temperature. We therefore investigate a possible temperature dependence of $\mathrm{C}$ by using room temperature (RT) data with glasses having very different glass transition temperatures $\left(\mathrm{T}_{g}\right)$. In doing so we were able to investigate a reduced temperature range (room temperature to glass transition temperature ratio) spanning from $\sim 0.3$ to 0.95 . However, we consider only compositions where both values of $\mathrm{H}$ and $\mathrm{Y}$ are available and are ranging from 0.3 to 0.75 . Values are reported in Table 1, along with the values of the yield strain $\epsilon_{y}$ and drawn on Figure 1.

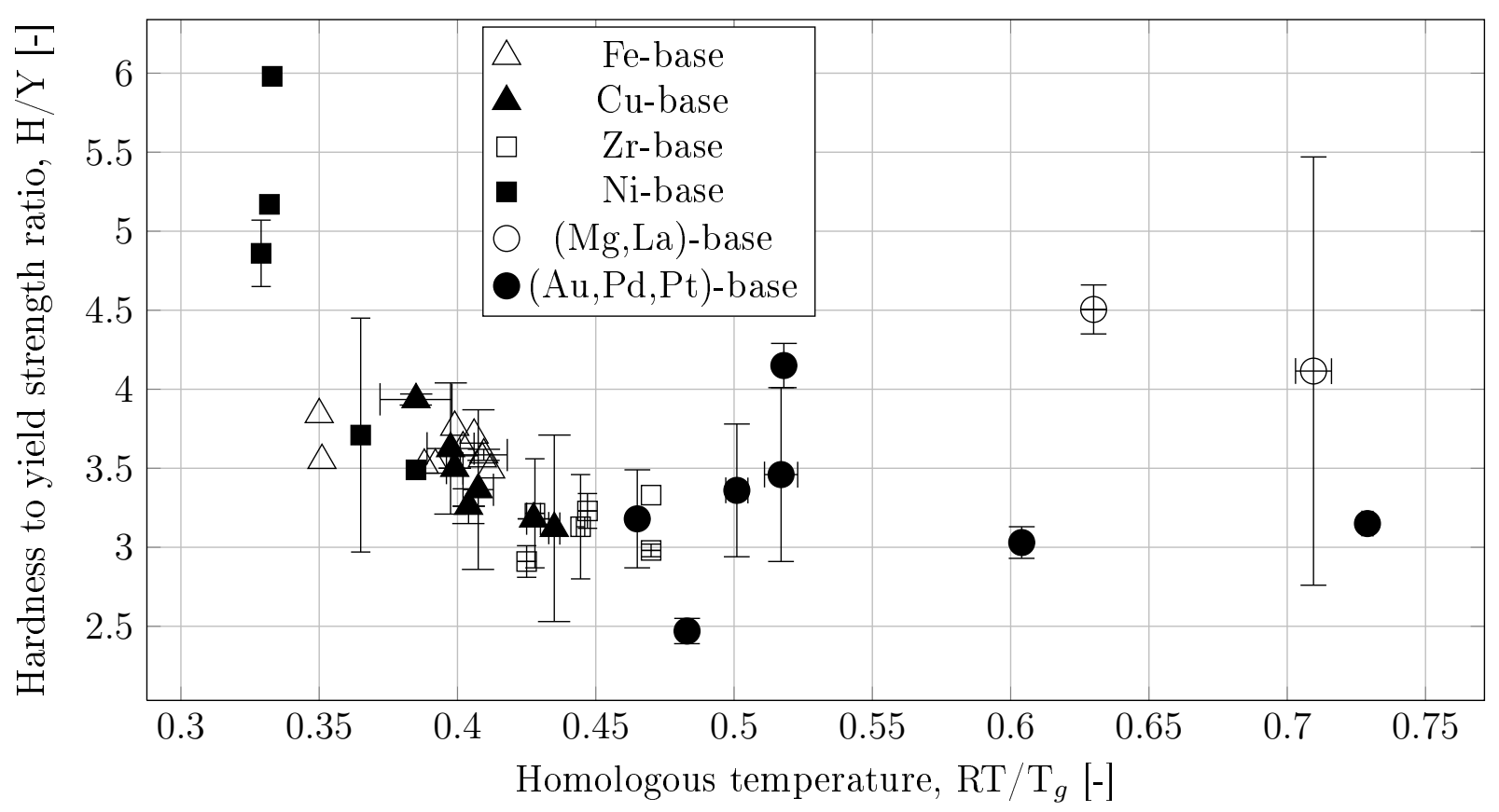

Fig. 1. Hardness-to-yield strength ratio as a function of reduced temperature $R T / T_{g}$ for all metallic glasses (RT refers to room temperature)

\section{Discussion}

According to Figure 1, for the data considered in the present work, one can distinguish two domains: for $\mathrm{RT} / \mathrm{T}_{g}$ lower than 0.4 , the ratio $\mathrm{H} / \mathrm{Y}$ clearly decreases with increasing reduced temperature, whereas for $\mathrm{RT} / \mathrm{T}_{g}$ greater than 0.4 , the ratio $\mathrm{H} / \mathrm{Y}$ seems to slightly increase 
with increasing reduced temperature. It is evident that such a scatter in data can not be so conclusive. Reasons of such as a scatter of data are discussed now. They are twofold. The first issue deals with the correct value of hardness while the second one concerns yield strength.

For the former, we must recall that $\mathrm{C}$ is the value for the ratio $\mathrm{H} / \mathrm{Y}$ in the fully plastic regime of indentation. The concept of indentation regime is illustrated in Figure 2. In the elastic regime (E), which is encountered for blunt indenters and small loads, only elastic strains develop during loading and disappear with unloading. In the elasto-plastic regime (EP), elastic and plastic strains develop during loading, leading to the formation of an imprint after unloading. This case is encountered for blunt indenters like spheres for higher loads (as compared to the previous regime) or for sharp indenters like cones for relatively large apex angles (as compared to the yield strain of the material as explained later). The ratio $\mathrm{H} / \mathrm{Y}$ depends strongly on the indenter geometry (sharp case) or on the load (blunt case). The fully plastic regime (FP) corresponds to even higher loads for blunt indenters or sharper indenters (lower apex angle). Let us notice that for sharp indenters the regime does not depend on the applied load. In the last case, the plastic zone is no longer fully contained by the surrounding elastic one and reaches the free surface. The ratio $\mathrm{H} / \mathrm{Y}$ is constant, with respect to geometry or load, and called $\mathrm{C}$.

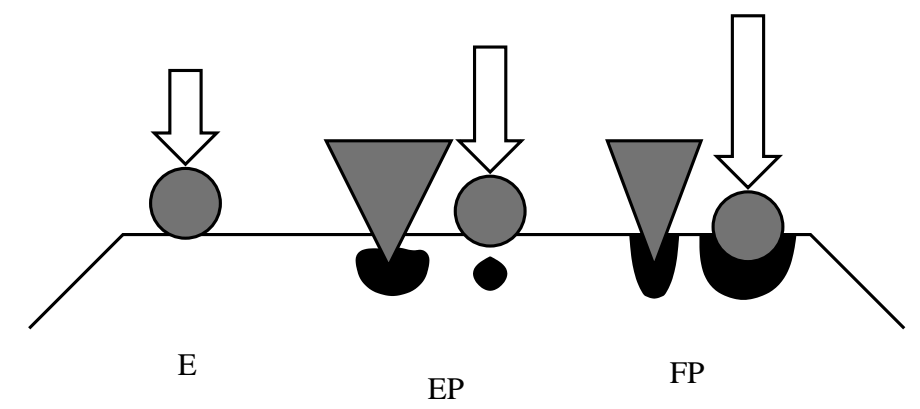

Fig. 2. The three indentation regimes ( $E$ for elastic, EP for elasto-plastic and FP for fully plastic) underneath an indenter, blunt like spheres or sharp like cones. Dark areas correspond to the plastic zone.

Keryvin [9] showed that a straightforward way to know whether the indention test is in fully plastic conditions is to look for shear bands around the imprints. These plasticity carriers are visible when material flows up at the free surface, as verified on different metallic glasses and by using different indenter geometries. However in the collected data collected, the presence of shear bands was rarely assessed.

Johnson [10] introduced the concept of a normalised indentation strain as the ratio of a representative strain generated by the indenter $\epsilon_{i}$ to the material yield strain $\epsilon_{y}$. Keryvin [9] showed that above a value of $\sim 30^{4}$, shear bands are observed around the imprints implying that the material is in FP conditions, while lower values would signify that hardness is underestimated. Apart from a few cases, collected literature values deal with a pyramidal Vickers indenter with a representative strain of $0.358\left(\tan \beta\right.$, where $\beta$ is the equivalent conical angle of $70.2^{\circ}$ ), which is known to be insufficient to enter the FP regime for some Zr-based compositions (high yield strains) and sufficient for some Pd-based compositions (lower yield strains). Moreover, it was reported that considering the equivalent cone for a pyramid was too conservative, and that a normalised indentation strain increased by eight should be taken. We therefore filtered the literature data of Fig. 1 keeping only FP values. Figure 3 is the result of such a filtering. Even if results of such a method indicate more clearly that the constraint factor increases with temperature, for $\mathrm{RT} / \mathrm{T}_{g}>0.4$, the scatter in data still remains and a definitive conclusion can not be drawn with ample confidence.

\footnotetext{
${ }^{4}$ In his original paper, he used a more complex formulation of the normalised indentation strain so that the critical value was around 25 .
} 
The second issue for handling literature data may also come from brittle compositions data including $\mathrm{Fe}, \mathrm{Ni}, \mathrm{Mg}$, or La-base alloys. For these compositions, and similarly to ceramics or oxide glasses, the fracture strength extracted from uniaxial experiments may be only a fraction of yield strength, even in compression, because of the sensitivity to surface defects. Moreover, cracking phenomena may be triggered when applying high enough loads by indentation [11]. For more malleable compositions ( $\mathrm{Pd}, \mathrm{Zr})$, a small amount of plastic deformation clearly indicates the transition from elasticity to plasticity, that is the yield strength.

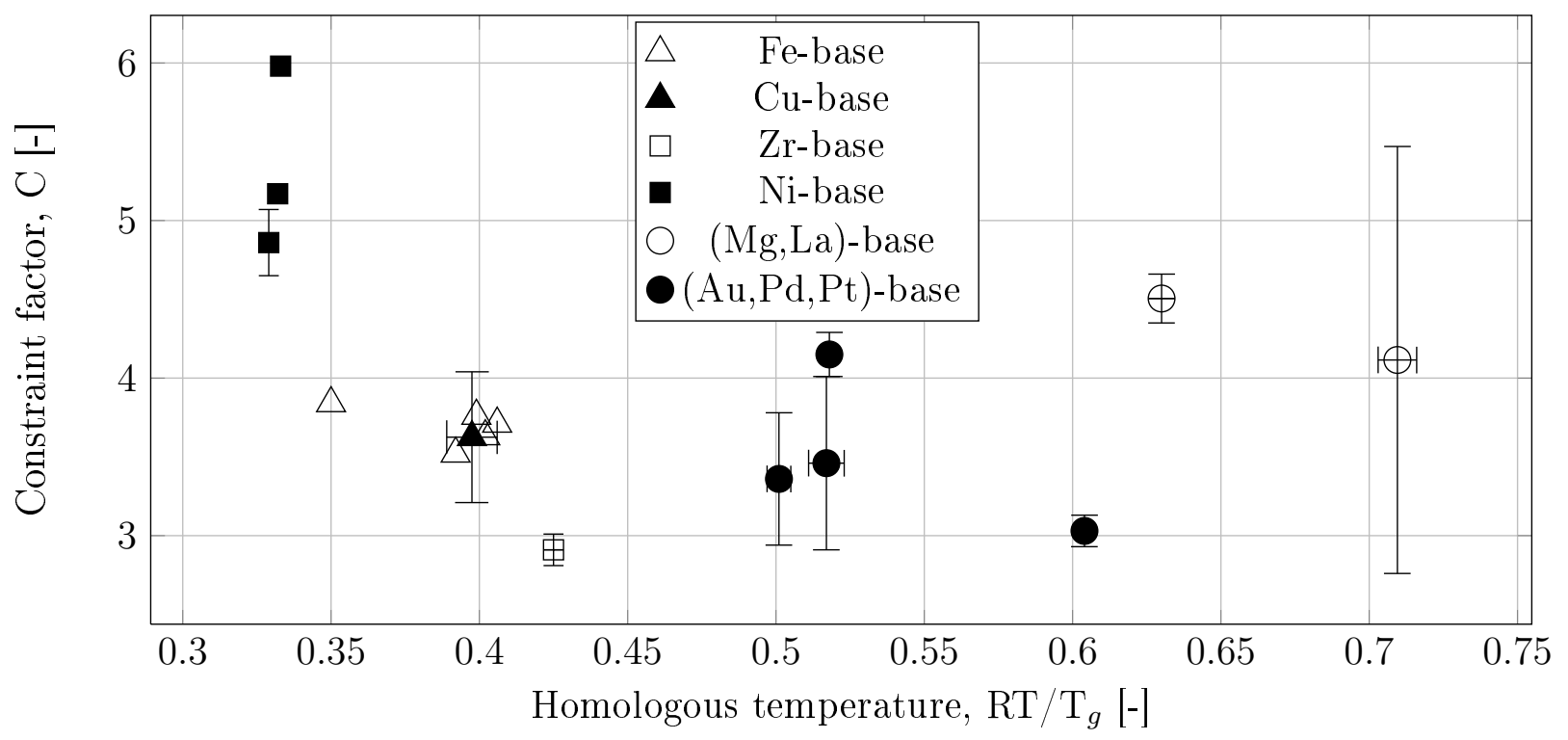

Fig. 3. Hardness-to-yield strength ratio (constraint factor) as a function of reduced temperature $R T / T_{g}$ for all metallic glasses in the fully plastic regime of indentation ( $R T$ refers to room temperature).

\section{Summary}

We have investigated, by a literature survey, the possibility that the pressure dependence of plasticity could increase in all metallic glasses with temperature below glass transition. However, the scatter originated from collecting hardness data in an inadequate indentation regime or from an underestimated yield strength for brittle compositions, made it impossible to draw decisive conclusions. It is expected, as performed in [6], that the reverse analysis of indentation loaddisplacements curves will solve this issue.

\section{References}

[1] Schuh, C. A., Hufnagel, T. C., and Ramamurty, U. Acta Mater. 55(12), 4067-4109 (2007).

[2] Keryvin, V., Nadot, Y., and Yokoyama, Y. Scripta Mater. 57, 145-148 (2007).

[3] Lund, A. C. and Schuh, C. A. Acta Mater. 51(18), 5399-5411 (2003).

[4] Keryvin, V., Crosnier, R., Laniel, R., Hoang, V. H., and Sanglebœuf, J.-C. J. Phys. D: Appl. Phys. 41(7), 074029 (2008).

[5] Keryvin, V. J. Phys.: Condens. Matter 20(11), 114119 (2008).

[6] Keryvin, V., Eswar Prasad, K., Gueguen, Y., Sanglebœuf, J.-C., and Ramamurty, U. Phil. Mag. 88(12), 1773-1790 (2008).

[7] Eswar Prasad, K., Raghavan, R., and Ramamurty, U. Scripta Mater. 57(2), 121-124 (2007).

[8] Eswar Prasad, K., Keryvin, V., and Ramamurty, U. J. Mater. Res. 24(3), 865-72 (2009).

[9] Keryvin, V. Acta Mater. 55, 2565-2578 (2007).

[10] Johnson, K. L. Contact Mechanics. Cambridge University Press, Cambridge, (1985).

[11] Keryvin, V., Vu, X.-D., Hoang, V., and Shen, J. J. All. Comp. 504S, S41-S44 (2010).

[12] Gu, X., Poon, S. J., Shiflet, G. J., and Widom, M. Acta Mater. 56(1), 88-94 (2008). 
[13] Inoue, A., Shen, B. L., and Chang, C. T. Acta Mater. 52(14), 4093-4099 (2004).

[14] Keryvin, V., Hoang, V. H., and Shen, J. Intermetallics 17(4), 211-7 (2009).

[15] Lee, S., Huh, M., Fleury, E., and Lee, J. Acta Mater. 54(2), 349-355 (2006).

[16] Yu, P., Bai, H., Tang, M., and Wang, W. J. Non-Cryst. Solids 351(14-15), 1328-1332 (2005).

[17] Wang, W. H. Progress in Materials Science 52(4), 540-596 (2007).

[18] Baser, T., Das, J., Eckert, J., and Baricco, M. J. Alloys Compd. 483(1-2), 146-149 (2009).

[19] Jiang, Q., Wang, X., Nie, X., Zhang, G., Ma, H., Fecht, H., Bendnarcik, J., Franz, H., Liu, Y., Cao, Q., and Jiang, J. Acta Mater. 56(8), 1785-1796 (2008).

[20] Yu, P. and Bai, H. Mater. Sci. Eng. A 485(1-2), 1-4 (2008).

[21] Cheung, T. and Shek, C. J. Alloys Compd. 434-435, 71-74 (2007).

[22] Xu, D., Lohwongwatana, B., Duan, G., Johnson, W. L., and Garland, C. Acta Mater. 52(9), 2621-2624 (2004).

[23] Louzguine, D. V. and Inoue, A. Mater. Sci. Eng. A 375-377, 346-350 (2004).

[24] Baricco, M., Baser, T., Das, J., and Eckert, J. J. Alloys Compd. 483(1-2), 125-131 (2009).

[25] Inoue, A., Zhang, W., Zhang, T., and Kurosaka, K. Acta Mater. 49(14), 2645-2652 (2001).

[26] Zhang, H. W., Subhash, G., Jing, X. N., Kecskes, L. J., and Dowding, R. J. Philos. Mag. Lett. 86(5), 333 (2006).

[27] Wang, W. J. Non-Cryst. Solids 351(16-17), 1481-1485 (2005).

[28] Li, W., Wei, B., Zhang, T., Xing, D., Zhang, L., and Wang, Y. Intermetallics 15(5-6), 706-710 (2007).

[29] Zhang, Q. S., Zhang, H. F., Deng, Y. F., Ding, B. Z., and Hu, Z. Q. Scr. Mater. 49(4), 273-278 (2003).

[30] Fan, G., Fu, L., Qiao, D., Choo, H., Liaw, P., Browning, N., and Loffler, J. J. Non-Cryst. Solids 353(44-46), 4218-4222 (2007).

[31] Wang, J., Zhao, D., Pan, M., Wang, W., Song, S., and Nieh, T. Scr. Mater. 62(7), 477-480 (2010).

[32] Lu, J., Ravichandran, G., and Johnson, W. L. Acta Mater. 51(12), 3429-3443 (2003).

[33] Kim, Y. J. Metals and Materials 1(2), 85-98 (1995).

[34] Xing, L. Q., Bertrand, C., Dallas, J. P., and Cornet, M. Mater. Sci. Eng. A 241(1-2), 216-225 (1998).

[35] Xing, D., Zhang, T., Li, W., and Wei, B. J. Alloys Compd. 433(1-2), 318-323 (2007).

[36] Wei, Y., Xi, X., Zhao, D., Pan, M., and Wang, W. Mater. Lett. 59(8-9), 945-947 (2005).

[37] Zhang, H., Subhash, G., Kecskes, L. J., and Dowding, R. J. Scr. Mater. 49(5), 447-452 (2003).

[38] Zhang, Y., Zhao, D. Q., Wang, R. J., and Wang, W. H. Acta Mater. 51(7), 1971-1979 (2003).

[39] Zhang, Y., Zhao, D. Q., Pan, M. X., and Wang, W. H. J. Non-Cryst. Solids 315(1-2), 206-210 (2003).

[40] Xu, D., Duan, G., Johnson, W. L., and Garland, C. Acta Mater. 52(12), 3493-3497 (2004).

[41] Choi-Yim, H., Xu, D., Lind, M. L., Loffler, J. F., and Johnson, W. L. Scr. Mater. 54(2), 187-190 (2006).

[42] Choi-Yim, H., Xu, D., and Johnson, W. L. Mater. Sci. Eng. A 449-451, 134-138 (2007).

[43] Santos, F., Sort, J., Fornell, J., Baro, M., Surinach, S., Bolfarini, C., Botta, W., and Kiminami, C. J. Non-Cryst. Solids 356(43), 2251-2257 (2010).

[44] Yuan, G. and Inoue, A. J. Alloys Compd. 387(1-2), 134-138 (2005).

[45] Li, Z., Hui, X., Zhang, C., and Chen, G. J. Alloys Compd. 454(1-2), 168-173 (2008).

[46] Zheng, Q., Ma, H., Ma, E., and Xu, J. Scr. Mater. 55(6), 541-544 (2006).

[47] Hodge, A. M. and Nieh, T. G. Intermetallics 12(7-9), 741-748 (2004).

[48] Wang, W. H., Dong, C., and Shek, C. H. Mater. Sci. Eng. A 44(2-3), 45-89 (2004).

[49] Shoji, T., Kawamura, Y., and Ohno, Y. Mater. Sci. Eng. A 375-377, 394-398 (2004).

[50] Wang, G., Liaw, P., Yokoyama, Y., Inoue, A., and Liu, C. Mater. Sci. Eng. A 494(1-2), 314-323 (2008).

[51] Lee, C., Lai, Y., Tang, C., Huang, J., and Jang, J. Mater. Trans. 50(12), 2795-2800 (2009).

[52] Schroers, J., Lohwongwatana, B., Johnson, W. L., and Peker, A. Appl. Phys. Lett. 87(6), 061912 (2005).

[53] Suryanarayana, C. and Inoue, A. Bulk Metallic Glasses. CRC Press LLC, (2010). 


\begin{tabular}{|c|c|c|c|c|c|c|c|c|}
\hline Composition (at. \%) & Ref. & H (GPa) & Y (GPa) & $\frac{\mathbf{H}}{\mathbf{Y}}(-)$ & $\epsilon_{y}(-)$ & $\frac{\epsilon_{i}}{\epsilon_{y}}+\mathbf{8}$ & Regime & $\frac{\mathbf{R T}}{\mathbf{T}_{g}}$ \\
\hline $\mathrm{Fe}_{66} \mathrm{Mo}_{10} \mathrm{P}_{12} \mathrm{C}_{10} \mathrm{~B}_{2}$ & [12] & 9.45 & 2.55 & 3.71 & 0.0145 & 32.7 & FP & 0.406 \\
\hline $\mathrm{Fe}_{64} \mathrm{Cr}_{3} \mathrm{Mo}_{10} \mathrm{P}_{10} \mathrm{C}_{10} \mathrm{~B}_{3}$ & {$[12]$} & 9.97 & 2.75 & 3.63 & 0.0156 & 30.9 & $\mathrm{FP}$ & 0.402 \\
\hline $\mathrm{Fe}_{63} \mathrm{Cr}_{3} \mathrm{Moo}_{10} \mathrm{P}_{12} \mathrm{C}_{10} \mathrm{~B}_{2}$ & [12] & 9.77 & 2.60 & 3.76 & 0.0146 & 32.5 & FP & 0.399 \\
\hline $\mathrm{Fe}_{63} \mathrm{Cr}_{3} \mathrm{Mo}_{12} \mathrm{P}_{10} \mathrm{C}_{7} \mathrm{~B}_{5}$ & [12] & 10.2 & 2.90 & 3.52 & 0.0158 & 30.6 & FP & 0.392 \\
\hline $\mathrm{Fe}_{65} \mathrm{Cr}_{2} \mathrm{Mog}_{9} \mathrm{P}_{10} \mathrm{C}_{8} \mathrm{~B}_{6}$ & {$[12]$} & 10.2 & 2.90 & 3.52 & 0.0163 & 29.9 & EP & 0.388 \\
\hline$\left(\mathrm{Fe}_{0.75} \mathrm{~B}_{0.2} \mathrm{Si}_{0.05}\right)_{96} \mathrm{Nb}_{4}$ & [13] & 11.2 & 3.16 & 3.55 & 0.0176 & 28.4 & $\mathrm{EP}$ & 0.351 \\
\hline $\mathrm{Fe}_{41} \mathrm{Co}_{7} \mathrm{Cr}_{15} \mathrm{Mo}_{14} \mathrm{C}_{15} \mathrm{~B}_{6} \mathrm{Y}_{2}$ & {$[14]$} & 13.45 & 3.5 & 3.84 & 0.0154 & 31.3 & $\mathrm{FP}$ & 0.35 \\
\hline$\overline{\mathrm{Cu}_{50} \mathrm{Zr}_{50}}$ & {$[15-21]$} & 4.71 & $1.27-1.86$ & $2.53-3.71$ & $0.0122-0.0221$ & $24.2-37.3$ & EP-FP & $0.433-0.437$ \\
\hline $\mathrm{Cu}_{64} \mathrm{Zr}_{36}$ & {$[15,22]$} & 7.79 & $1.96-2.00$ & $3.90-3.97$ & $0.0212-0.0217$ & $24.5-24.9$ & $\mathrm{EP}$ & $0.372-0.398$ \\
\hline$\left(\mathrm{Cu}_{50} \mathrm{Zr}_{50}\right)_{96} \mathrm{Al}_{4}$ & {$[16,20,21]$} & 5.13 & 1.61 & 3.18 & $0.0150-0.0182$ & 27.7-31.9 & EP-FP & $0.425-0.430$ \\
\hline $\mathrm{Cu}_{60} \mathrm{Hf}_{25} \mathrm{Ti}_{15}$ & {$[23-25]$} & 7.03 & 2.01 & 3.50 & $0.0162-0.0168$ & $29.4-30.1$ & EP-FP & $0.397-0.401$ \\
\hline $\mathrm{Cu}_{60} \mathrm{Hf}_{30} \mathrm{Ti}_{10}$ & {$[25,26]$} & $6.30-6.74$ & 2 & $3.15-3.37$ & 0.0168 & 29.3 & $\mathrm{EP}$ & 0.404 \\
\hline $\mathrm{Cu}_{60} \mathrm{Zr}_{20} \mathrm{Hf}_{10} \mathrm{Ti}_{10}$ & {$[15,27,28]$} & $7-8.8$ & 2.18 & $3.21-4.04$ & $0.0166-0.0216$ & $24.6-29.3$ & FP & $0.389-0.406$ \\
\hline $\mathrm{Cu}_{60} \mathrm{Zr}_{30} \mathrm{Ti}_{10}$ & {$[15,23-25,29,30]$} & $6.04-6.93$ & $1.79-2.11$ & $2.86-3.87$ & $0.0157-0.0188$ & $19.0-22.8$ & $\mathrm{EP}$ & $0.402-0.413$ \\
\hline $\mathrm{Zr}_{46.75} \mathrm{Ti}_{8.25} \mathrm{Cu}_{7.5} \mathrm{Ni}_{10} \mathrm{Be}_{27.5}$ & {$[27,31]$} & 6.10 & 1.83 & 3.33 & 0.0183 & 27.6 & $\mathrm{EP}$ & 0.470 \\
\hline $\mathrm{Zr}_{41.2} \mathrm{Ti}_{13.8} \mathrm{Cu}_{12.5} \mathrm{Ni}_{10} \mathrm{Be}_{22.5}$ & {$[31-33]$} & $5.61-5.62$ & $1.86-1.91$ & 2.94-3.02 & 0.0194-0.0199 & 26.5 & EP & 0.470 \\
\hline $\mathrm{Zr}_{57} \mathrm{Cu}_{20} \mathrm{Al}_{10} \mathrm{Ni}_{8} \mathrm{Ti}_{5}$ & [34] & $4.60-5.40$ & $1.56-1.64$ & $2.80-3.46$ & $0.0183-0.0252$ & $22.2-27.5$ & EP & $0.443-0.446$ \\
\hline $\mathrm{Zr}_{52.5} \mathrm{Al}_{10} \mathrm{Ni}_{20} \mathrm{Cu}_{15} \mathrm{Be}_{12.5}$ & {$[35-37]$} & $5.00-5.35$ & 1.78 & $2.81-3.01$ & 0.0186 & $32.7\left(\epsilon_{\mathrm{i}}=0.46\right)$ & FP & 0.425 \\
\hline $\mathrm{Zr}_{52.5} \mathrm{Al}_{10} \mathrm{Ni}_{14.6} \mathrm{Cu}_{17.9} \mathrm{Ti}_{5}$ & {$[26,37]$} & $5.00-6.20$ & 1.74 & $2.87-3.56$ & 0.0187 & $27.1\left(\epsilon_{\mathrm{i}}=0.46\right)$ & $\mathrm{EP}$ & 0.428 \\
\hline $\mathrm{Zr}_{48} \mathrm{Nb}_{8} \mathrm{Cu}_{14} \mathrm{Ni}_{12} \mathrm{Be}_{18}$ & {$[31,38,39]$} & $6.09-6.52$ & 1.95 & $3.12-3.34$ & 0.0208 & 25.2 & $\mathrm{EP}$ & 0.447 \\
\hline $\mathrm{Ni}_{40} \mathrm{Ti}_{17} \mathrm{Zr}_{28} \mathrm{Al}_{10} \mathrm{Cu}_{5}$ & {$[31,40]$} & 9.05 & 2.59 & 3.49 & 0.0193 & 26.5 & $\mathrm{EP}$ & 0.385 \\
\hline $\mathrm{Ni}_{60} \mathrm{Nb}_{37} \mathrm{Sn}_{3}$ & {$[28,41,42]$} & $13.02-14.2$ & 2.8 & $4.65-5.07$ & $0.0129-0.0141$ & $32.4-35.8$ & FP & $0.328-0.330$ \\
\hline $\mathrm{Ni}_{60} \mathrm{Nb}_{33.8} \mathrm{Sn}_{6.2}$ & {$[41,42]$} & 13.44 & 2.3 & 5.17 & 0.0125 & 36.64 & FP & 0.332 \\
\hline $\mathrm{Ni}_{60} \mathrm{Nb}_{33.1} \mathrm{Sn}_{6.9}$ & {$[41,42]$} & 10.76 & 1.8 & 5.98 & 0.00972 & 44.8 & FP & 0.333 \\
\hline $\mathrm{Ni}_{50} \mathrm{Nb}_{28} \mathrm{Zr}_{22}$ & [43] & $9.5-11.13$ & $2.5-3.2$ & $2.97-4.45$ & $0.0253-0.0360$ & $20.8-26.2$ & $\mathrm{EP}$ & $0.363-0.367$ \\
\hline $\mathrm{Mg}_{65} \mathrm{Cu}_{25} \mathrm{Gd}_{10}$ & {$[28,31,35,44-46]$} & $2.70-2.89$ & $0.528-0.98$ & $2.76-5.47$ & $0.00807-0.0200$ & $25.9-52.3$ & FP & $0.703-0.716$ \\
\hline $\mathrm{La}_{55} \mathrm{Al}_{25} \mathrm{Cu}_{10} \mathrm{Ni}_{5} \mathrm{Co}_{5}$ & {$[31,47,48]$} & $3.7-3.96$ & 0.85 & $4.35-4.66$ & 0.0165 & $35.9\left(\epsilon_{\mathrm{i}}=0.46\right)$ & $\mathrm{FP}$ & 0.630 \\
\hline $\mathrm{Pd}_{43} \mathrm{Ni}_{10} \mathrm{Cu}_{27} \mathrm{P}_{20}$ & {$[28,35]$} & $7.30-7.81$ & 1.82 & $4.01-4.29$ & 0.0148 & 32.2 & $\mathrm{FH}$ & 0.518 \\
\hline $\mathrm{Pd}_{40} \mathrm{Cu}_{30} \mathrm{P}_{20} \mathrm{Ni}_{10}$ & {$[27,31,47,49]$} & $5.00-7.38$ & 1.72 & $2.91-4.01$ & $0.0150-0.0176$ & $28.3-38.7\left(\epsilon_{\mathrm{i}}=0.358-0.46\right)$ & EP-FP & $0.511-0.523$ \\
\hline $\mathrm{Pd}_{40} \mathrm{Ni}_{40} \mathrm{P}_{20}$ & {$[9,24,26,27,47,49]$} & $5.30-6.80$ & $1.70-1.80$ & $2.94-3.78$ & $0.0146-0.0167$ & $29.4-39.5\left(\epsilon_{\mathrm{i}}=0.358-0.46\right)$ & EP-FP & $0.497-0.505$ \\
\hline $\mathrm{Pd}_{77.5} \mathrm{Si}_{16.5} \mathrm{Cu}_{6}$ & {$[24,26,27,31]$} & $4.50-5.24$ & $1.50-1.57$ & $2.87-3.49$ & $0.0161-0.0178$ & $28.1-30.2$ & EP-FP & 0.465 \\
\hline $\mathrm{Pd}_{80} \mathrm{Si}_{20}$ & {$[24,26,27,50]$} & $3.20-3.42$ & 1.34 & $2.39-2.55$ & $0.0191-0.0200$ & $25.9-26.7$ & $\mathrm{EP}$ & 0.483 \\
\hline $\mathrm{Pt}_{60} \mathrm{Ni}_{15} \mathrm{P}_{25}$ & {$[27,31]$} & 4.1-4.39 & 1.4 & $2.93-3.13$ & 0.0146 & 32.5 & FP & 0.604 \\
\hline $\mathrm{Au}_{49} \mathrm{Ag}_{5.5} \mathrm{Pd}_{2.3} \mathrm{Cu}_{26.9} \mathrm{Si}_{16.3}$ & {$[31,51-53]$} & 3.78 & 1.2 & 3.15 & $0.0161-0.0171$ & $28.9-30.2$ & EP-FP & $0.727-0.731$ \\
\hline
\end{tabular}

Table 1. Mechanical properties of metallic glasses: $H$ stands for Meyer's hardness, $Y$ for the compressive yield strength, $\epsilon_{y}$ for compressive yield strain, $\epsilon_{i}$ for the representative indentation strain, $R T$ for room temperature and $T_{g}$ for glass transition temperature. Unless specified, $\epsilon_{i}=0.358$. 